\title{
Piston Crown Profile Modifications for Various Combustion Mode Strategies of Modified GDI Engine towards NOx and PM Reduction
}

\author{
Shivakumar N \\ 0000-0001-9084-9101 \\ Mechanical Engineering Department, Aarupadai Veedu Institute of Technology, Vinayaka Mission's Research Foundation, Chennai, India,
}

\begin{abstract}
In the current development of automotive engines, the major target is to design a combustion chamber in such a way that the combustion process must provide very less concentrations of emissions. To satisfy current worldwide emission norms, petrol engines also equipped with direct fuel injection (gasoline/petrol directly injected into engine cylinder) same as like diesel engines. The main drawback of GDI engine is NOx and PM emissions due to lean burn combustion and rich mixture formation over the combustion chamber surface because of wall wetting. In GDI engines, the gasoline fuel injector is placed at various positions with different angles over an engine cylinder head as per the mode of combustion strategy. Based on the mode of combustion with fuel injection angle, the piston crown shape design in much important that the crown surface must not involved in wall wetting during injection. The piston crown shapes were modified for Spray guided combustion mode, Wall guided combustion mode and Air guided combustion mode by keeping in mind that the position of injector with fuel spray angle and the position of spark plug tip on the cylinder head. The main aim of modifying the crown surface profiles of piston is to impart swirl and squish effects for better mixing of air and injected fuel, maintain combustion chamber surface temperature range within the limits and also to avoid wall wetting results in chances of reducing soot particle/PM emission and NOx emission from combustion process.
\end{abstract}

Keywords: Combustion modes; Crown profiles, GDI engine; Piston shapes.
* Corresponding author

Shivakumar N

shiva.thermal@gmail.com

Adress: Department of Mechanical Engineering , Aarupadai Veedu Institute of Technology, Chennai, India.

Tel:+91 9360429581

Researh Article

Manuscript

Received 17.09.2020

Revised $\quad 06.10 .2020$

Accepted 10.11.2020

Doi: $10.30939 /$ ijastech..796526

\section{Introduction}

With the increase in global energy demand and population, it is mandatory to improve fuel economy and reduce the emission concentrations evolving from automobiles. The primary level of reducing emissions from automobiles is within the combustion chamber i.e., during combustion process. The drawback of GDI engine is NOx and PM emissions and the reason for these emissions is high temperature ranges with the cylinder and rich mixture formation over the surface of combustion chamber. In order to maintain the in-cylinder temperature ranges within the limits, the base temperature values over the surface of combustion chamber were measured using K-type thermocouples and the heat transfer related terms were calculated $[1,2]$.
To achieve the high degree of stratification charge, the accurate control of fuel injection timing is important. Advancing and retarding the fuel injection timing, deteriorate the mixture formation therefore there is an optimization value of fuel injection timing. For the investigated piston B (Piston A has large bowl and Piston B has small bowl), the injection timing of $300^{\circ} \mathrm{CA}$ aTDC is more appropriate at ignition timing of $345^{\circ} \mathrm{CA}$ aTDC compared to other crank angles [3].

Saw et al. [4] conducted CFD simulation study on a $4 \mathrm{~S}$ four valve GDI engine with four different positions of spark plug and fuel injector, it is observed that the better mixture stratification, higher in-cylinder pressure \& temperature, heat release rate and faster burning were found for the case where the spark plug is positioned centrally with inclined fuel injection. Also $\mathrm{CO}$ and soot emissions are least and NOx emission was higher in this case. 
3D-CFD simulations are used to study the effect of piston bowl shapes and direct injection strategies on the incylinder conditions. Among shallow bowl and deep bowl piston modifications, the deep bowl piston shape shows increased GDI ratio and advanced injection timing could increase the fuel evaporation ratio [5]. The study on the effect of engine speed and inlet air pressure on the mixture stratification in a wall guided GDI engine shows the percentage of fuel evaporated at the time of spark, increases by about $1.7 \%$ and decreases by about $3 \%$, when the engine speed increases to $3000 \mathrm{rev} / \mathrm{min}$ and $4000 \mathrm{rev} / \mathrm{min}$., respectively from $2000 \mathrm{rev} / \mathrm{min}$. And the percentage of fuel evaporated increases by about $0.5 \%$ and $1.5 \%$, when the inlet air pressure changes to 1.2 bar and 1.4 bar respectively from 1 bar [6]

P R Ganji et al. studied on the effect of different piston bowl geometries such as Hemispherical bowl, Shallow bowl and Toroidal bowl at constant speed and load were analyzed using CFD software and the results show that toroidal piston bowl shape is found to be the better among the three shapes in terms of ISFC and soot but resulted in higher NOx emissions. The depth of bowl $20.30 \mathrm{~mm}$ of the toroidal bowl shape is found to be the optimum, and the corresponding NOx and soot emissions are lower by $71 \%$ and $41 \%$, respectively, as compared to toroidal baseline [7].

The geometry of the piston is modified by accommodating rotating blades in the piston crown to induce turbulence by means of swirl motion of charge. The brake specific fuel consumption is found to be $0.282 \mathrm{~kg} / \mathrm{kw}-\mathrm{hr}$ for normal piston and $0.258 \mathrm{~kg} / \mathrm{kwhr}$ for swirl piston at advanced injection timing. From the results, $8.5 \%$ decrement of the brake specific fuel consumption observed for swirl piston compared to normal piston with 300 bar pressure and advanced injection timing at $80 \%$ load. The brake thermal efficiency with 300 bar pressure and advanced injection timing at $80 \%$ load is found to be maximum value of $31.75 \%$ for swirl piston and it is $28.99 \%$ of normal piston which is an approximate rise of 2-3\% at every load and injection timings. The $\mathrm{HC}$ emission with the use of swirl piston, there has been a considerable decrement was noticed compared to normal piston even at $80 \%$ load with advanced injection timing. The NOx emissions are 275 ppm for swirl piston and 358 ppm for normal piston with 300 bar pressure and standard injection timing at $80 \%$ load [8]

On evaluating the effect of piston shape on in-cylinder flows in a direct injection engine using CFD, two pistonshapes namely flat and bowl types at wide-open-throttle under non-firing conditions are considered. From the analysis of results, it is found that bowl shaped piston generates higher TR and TKE than those of flat piston by about $15 \%$ and $12 \%$ respectively [9].

In the comparison of the flow velocity, it was found that the shape of the bottom of the double circle was greater than that of the single circle shape, results in better mixing of air and fuel, thereby reducing exhaust emissions. During the combustion process, it was conclude that the shape of the double round bottom is more effective than the other shapes in promoting the mixing of air and fuel by comparing other shapes [10].

The omega shape piston bowl provides reduction of NOx and soot particles emissions by $75 \%$ and $20 \%$ each respectively when compare with single curved piston bowl and deep piston bowl [11].

\section{GDI Engine Combustion}

In Petrol engine, there are various stages of development in order to satisfy the continuous regulations of emission norms viz., the transition from Carburetor to Throttle injection, Throttle injection to Port/Manifold injection and them Manifold injection to Direct injection. Currently GDI engines with precise control of electronic system satisfy the advanced emission norms from petrol fuel. In GDI engines the gasoline/petrol is directly injected into the cylinder either during suction or compression strokes (or) during both the strokes.

\subsection{GDI Engine Combustion Modes}

There are the three modes of combustion strategies in GDI engine namely Spray guided, Wall guided and Air guided. In each combustion mode, the position of spark plug is at the centre of combustion chamber to maintain equal flame travel distance but the position of fuel injector is different based on the mode of combustion or the shape of piston crown. In case of spray guided combustion mode, the fuel injector and spark plug are placed almost centre of combustion chamber as shown in figure 1. In spray guided combustion mode, the injector is placed vertically so that the injected fuel distributes throughout the combustion chamber volume and the piston crown profile is either flat or small shallow bowl at the centre of piston.

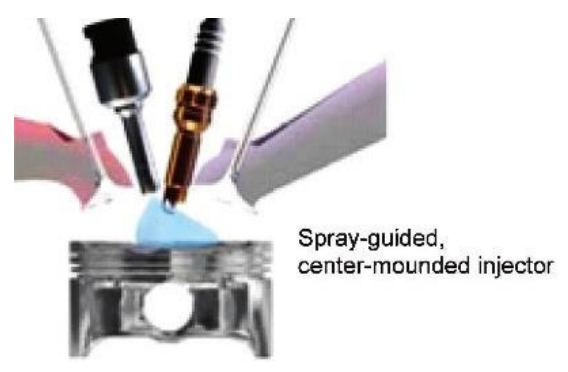

Fig. 1. Spray guided combustion mode

In case of wall guided combustion mode, the spark plug is placed at the centre of combustion chamber to maintain equal flame travel distance within the combustion chamber volume and the fuel injector is placed inclined so that the injected fuel slides over the deflector surface of piston and the flow of fuel vapor diverted towards the spark plug tip 
to initiate the combustion as shown in figure 2 . In wall guided combustion mode, the piston crown profile modified with offset bowl merged deflector in order to divert the injected fuel towards spark plug tip.

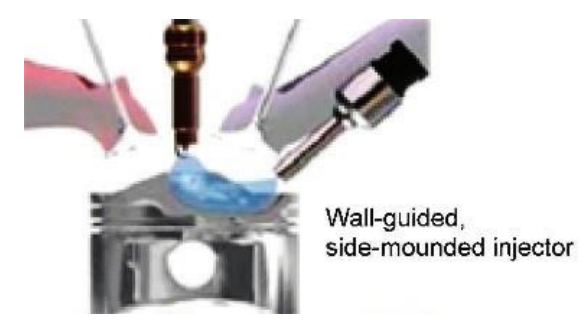

Fig. 2. Wall guided combustion mode

In case of air guided combustion mode, the spark plug is placed at the centre of combustion chamber to maintain equal flame travel distance within the combustion chamber volume and the fuel injector is placed inclined so that the injected fuel penetrate through the compressed air within the combustion chamber as shown in figure 3. In air guided combustion mode, the piston crown profile is flat.

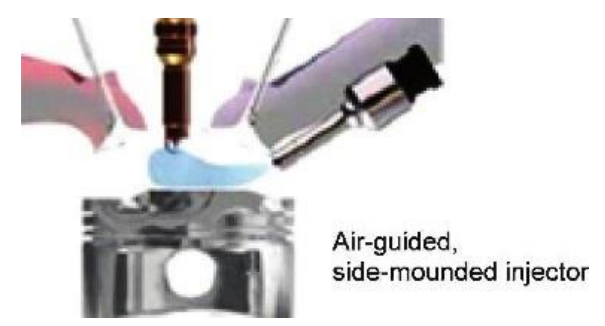

Fig. 3. Air guided combustion mode

\subsection{Advantages and Disadvantages of GDI Engine}

GDI engine is having more number of advantages except NOx and PM emissions. The advantages of GDI engine are as follows:

- More precise control of air-fuel ratio results in lower fuel consumption,

- Improved volumetric efficiency and more power output,

- Better vaporization and easy cold starting,

- Allows injection of fuel at any time during a cycle and

- $\quad$ Reduced $\mathrm{CO}_{2}$ emission.

\section{Methodology}

The hemispherical bowl pistons of Kirloskar 5HP diesel engine was modified into centre deep shallow bowl for spray guided combustion mode, small centre shallow bowl for air guided combustion mode and small offset bowl with deflector for wall guided combustion mode. In each combustion mode, the positions of fuel injector and spark plug were considered while modifying piston crown profile.
The following steps were taken place for modifying the piston crown surface:

- $\quad$ Selection of filler aluminium alloy for filling the base hemispherical piston bowl,

- Filling of hemispherical piston bowl with Tig welding,

- Machining on the piston crown surface using Lathe and Shaper machines, and

- Maintaining suitable compression ratio of an engine with further machining operations on the piston crown surface.

\section{Experimental Work}

The Kirloskar 5HP, water cooled, $1500 \mathrm{rpm}$ constant speed, stationary 4S-diesel engine is selected for modification into GDI engine where the base piston exists with hemispherical bowl. Before modifying pistons which suit for all three combustion modes, the existing hemispherical bowl was filled with suitable filling material using Tig welding. During piston crown surface modification, the compression ratio of modified GDI engine is taken into account whichever may be the combustion mode. The compression ratio of modified GDI engine is maintained at 10: 1 while modifying each piston with respect to the type of combustion mode.

\subsection{Piston Material Selection}

The piston crown area subjected to both structural (gas pressure) and thermal loads due to combustion of fuel-air mixture. These loads will be maximum at the beginning of expansion process once the combustion process complete. In order to withstand these loads the optimized piston head/crown thickness is to be maintained.

As a rule, a high thermal conductivity is benefit, because it provides uniform temperature distribution throughout the piston. Low temperatures not only allow greater loading of the material, but also have a beneficial effect on the process parameters at the piston crown, such as the volumetric efficiency and knock limit. Static and dynamic strength values describe material behaviour under isothermal conditions. Pistons are exposed to severe changes in temperature at times. The transient heat stresses that arise place cyclical loads on the material that can sometimes exceed the elastic limit. Materials must also be resistant to these stresses. Due to the motions and side thrust that occur at the sliding and sealing surfaces, piston materials must also meet high requirements for seizure resistance, low friction, and wear resistance. The material pairing of the piston and its sliding counterparts is particularly critical, as are the lubrication conditions.

In order to satisfy both thermal and structural loads acting on the piston crown surface, aluminium 4043 series alloy was used for filling the existing piston bowl through 
Tig welding. Figure 4 shows the $3 \mathrm{~mm}$ diameter 4043 series aluminium alloy rods used as filler material perfectly suits petrol engine piston material.

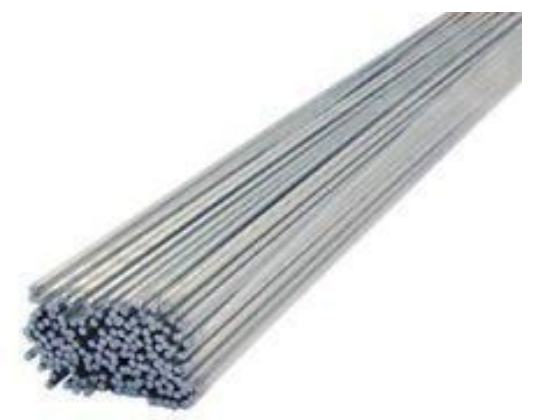

Fig. 4. 4043 series Aluminium alloy used as piston bowl filler material

\subsection{Modification of Pistons as per Combustion Mode}

The selected 4043 aluminium alloy material in the form of rods was used to fill the hemispherical bowl on the baseline piston using Tig welding with proper current supply. Figure 5 shows the filled hemispherical bowl piston with filler material using Tig welding. The thickness of filler material was maintained around $3 \mathrm{~mm}$ above the top baseline surface in order to avoid uneven surface finish after machining. The welded filler material was properly bonded without any blow holes or cracks since the composition of selected filler material and base piston material matched.

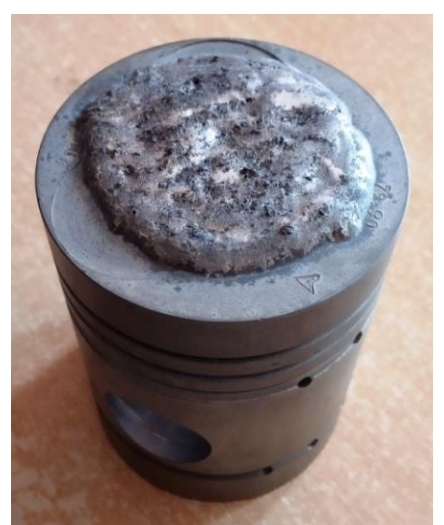

Fig. 5. Piston hemispherical bowl filled with 4043 Aluminium alloy

For spray guided combustion mode, the shape chosen for piston modification is deep shallow bowl in which there is no wall wetting of fuel over the surface of piston crown. The optimized minimum thickness of piston head/crown was maintained such that no failure of piston crown at high gas pressure with high temperature at the beginning of expansion process. The deep shallow bowl on the piston head was done with Lathe turning operation with necessary tool. Figure 6 shows the modified piston bowl for spray guided combustion mode strategy. Finally the modified piston crown profile for spray guided combustion mode was checked for correct compression ratio. In spray guided combustion mode, the fuel injector was placed vertically at the centre of combustion chamber/piston bowl so that the injected fuel spray occupies within the bowl or combustion chamber volume without major wall wetting of fuel on the piston crown surface.

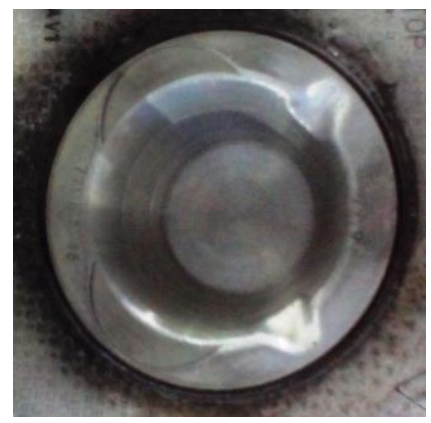

Fig. 6. Modified piston bowl for Spray guided combustion mode

For air guided combustion mode, the shape chosen for piston modification is small shallow bowl in which the fuel injector is placed inclined so that the injected fuel is sprayed through compressed air results in no wall wetting of fuel over the surface of piston crown. The optimized minimum thickness of piston head/crown was maintained such that no failure of piston crown at high gas pressure with high temperature at the beginning of expansion process. The small shallow bowl on the piston head was done with Lathe turning operation with necessary tool. Figure 7 shows the modified piston bowl for air guided combustion mode strategy. Finally the modified piston crown profile for air guided combustion mode was checked for correct compression ratio.

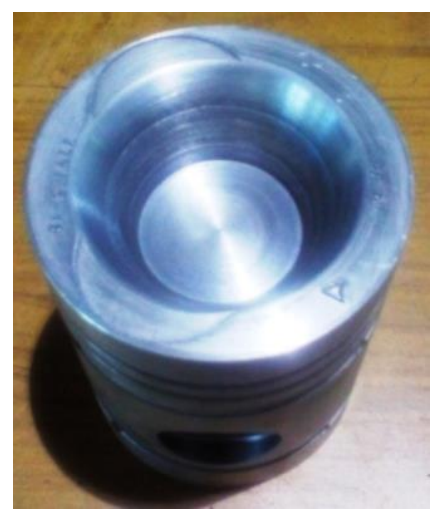

Fig. 7. Modified piston bowl for Air guided combustion mode

For wall guided combustion mode, the shape chosen for piston modification is offset bowl with wedge shape acts as deflector. The optimized minimum thickness of piston head/crown at the circumferential edge of piston was maintained such that no failure of piston crown at high gas 
pressure with high temperature at the beginning of expansion process. The wedge shape on the piston head was done with Shaping operation and the offset bowl made by Lathe turning operation. Figure 8 shows the modified piston profile for wall guided combustion mode strategy. Finally the modified piston crown profile for wall guided combustion mode was checked for correct compression ratio. In wall guided combustion mode, the fuel injector was inclined so that the injected fuel slides over the offset bowl surface on the piston crown and the flow directed towards the tip of spark plug to initiate the combustion of air-fuel mixture.

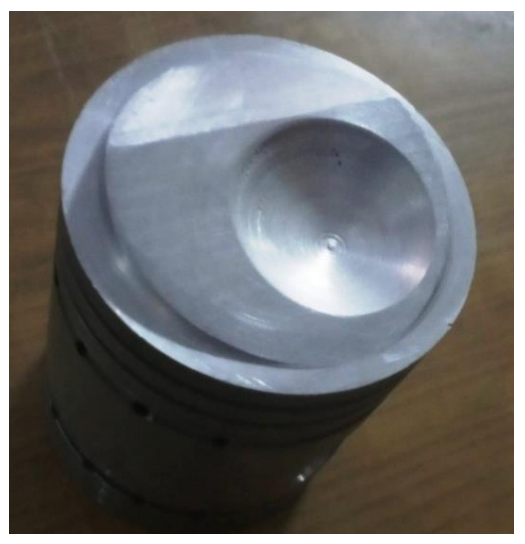

Fig. 8. Modified piston profile for Wall guided combustion mode

\section{Results and Discussions}

From the modified piston profiles for spray guided, air guided and wall guided combustion mode strategies, the following point were discussed:

- The deep shallow bowl and small shall bowl piston profiles can be used for spray guided combustion mode but deep shallow bowl piston profile cannot be used for air guided combustion mode strategy.

- With the use of shallow bowl piston profiles, no wall wetting of fuel over the surface of piston crown.

- The piston crown with offset bowl with wedge shape deflector modified for wall guided combustion mode is also used for the combined air-wall guided combustion mode for better results towards engine performance and emission control.

- In wall guided or combined air-wall guided combustion mode, the injected fuel slides over the offset bowl surface on the piston crown and the flow directed towards the tip of spark plug to initiate the combustion of air-fuel mixture.

- Irrespective of the piston shape and combustion mode, dual or multiple injections results in reduction of $\mathrm{NOx}$ emission and knocking tendency.

\section{Conclusions}

The piston crown shapes were modified for Spray guided combustion mode, Wall guided combustion mode and Air guided combustion mode by keeping in mind that the position of injector with fuel spray angle and the position of spark plug tip on the cylinder head. The main aim of modifying the crown surface profiles of piston is to impart swirl and squish effects for better mixing of air and injected fuel, maintain combustion chamber surface temperature range within the limits and also to avoid wall wetting results in chances of reducing soot particle/PM emission and NOx emission from combustion process.

Future Work: The modified pistons are to be tested experimentally for NOx and PM emissions with assembling pistons in modified GDI engine.

\section{References}

[1] Nagareddy S., (2017). Temperature distribution measurement on combustion chamber surface of diesel engine-experimental method, International Journal of Automotive Science and Technology, 1(3), 8-11.

[2] Kumar, Shiva \& Kumar, Ajeet \& Sharama, Abhilash \& Kumar, Amit. (2018). Heat transfer correlations on combustion chamber surface of diesel engine - experimental work. International Journal of Automotive Science and Technology. 2835. 10.30939/ijastech..434331.

[3] Qianwang, F., Zongjie, H., Jun, D., and Liguang, L., (2010). Stratified mixture formation and combution process for wall guided stratified charge DISI engines with different piston bowls by simulation. SAE International, 2010-01-0595.

[4] Saw, O.P., and Mallikarjuna, J.M., (2017). Effect of spark plug and fuel injector location on mixture stratification in a GDI engine - A CFD analysis. IOP Conference Series: Materials Science and Engineering, 243(1), 1-12.

[5] Xinyan, W., Hua, Z., Hui, X., and Bq, H., (2014). Numerical study of the effect of piston shapes and fuel injection strategies on In-cylinder conditions in a PFI/GDI gasoline engine. SAE International Journal of Engines.

[6] Krishna, A.S., and Mallikarjuna, J.M., (2017). Effect of engine parameters on mixture stratification in a wall guided GDI engine - a quantitative CFD analysis. SAE International Journal of Commercial Vehicles.

[7] Prabhakara, R., Ganji, Rudra, N.S., Raju, V.R.K., and Srinivasa, R., (2018). Design of piston bowl geometry for better combustion in direct-injection compression ignition engine. Indian Academy of Sciences, Sadhana 43(6), 92.

[8] Kumar, K.V., Damera, B., Sunchu, A., Sunchu, A., Srinivasa, R., and Shailesh, P., (2018). Investigation of diesel engine performance with design modifications in piston: inducing turbulence by swirl. International Journal of Mechanical Engineering and Robotics Research, 7(5), 495-499. 
[9] Kumar, J.S., Ganesan, V., Mallikarjuna, J.M., and Srinivasan, G., (2013). Effect of piston crown shape on in-cylinder flow characteristics in a direct injection engine - a CFD study. $S A E$ International Journal of Engines, 2013-01-2797.

[10] Changchun Xu, Md. Abu Kalam, HaengMuk Cho, (2018). The study on the effect of the piston shapes through biodiesel mixture combustion in diesel engine. E3S Web of Conferences 53, 03022.

[11] Kianoosh S, and Majid M, (2019). Designing different piston bowls for reduction of emissions and improvement of power parameters in a dimethyl ether-burning diesel engine. Journal of Energy Management and Technology, 1810-1133. 